\title{
A PC-BASED PORTABLE ICE-RADAR RECEIVER
}

\author{
By W.R. HAMMOND and K.F. SPRENKE
}

(Department of Geology and Geological Engineering, University of Idaho, Moscow, Idaho 83843, U.S.A.)

ABstract. We have assembled a low-cost portable ice-radar receiver that is based on a personal computer (PC). The unit consists of a digital storage oscilloscope controlled by a lap-top PC. The total weight is $22 \mathrm{~kg}$. The radar wave forms are digitized by the oscilloscope, displayed on the computer screen, and stored on a floppy diskette. All components are commercially available at a cost below $\$ 2000$ U.S. The radar receiver has proved to be very versatile because the computing capabilities of an IBM-compatible PC are available in the field to control signal acquisition, to display radar wave forms in near-real time, and to perform sophisticated signal processing as measurements are taken. The PC-based ice-radar receiver was used for ice-thickness and bedrock power-reflection coefficient surveys of Mount Estelle glacier in the Alaska Range, Alaska, in 1988.

\section{INTRODUCTION}

A light-weight and inexpensive radar sounder for temperate glaciers was developed in the 1970 s by the U.S. Geological Survey (Watts and England, 1976; Watts and Wright, 1981). We have extended the versatility of this sounder by including a low-cost digital receiver (Fig. 1). The receiver uses an IBM-compatible lap-top computer interfaced with a computer-controlled digital-storage oscilloscope. The computer acquires the radar wave forms, displays and processes the signals, and stores them on disk. Software allows wave-form stacking and measurement of time, voltage, and frequency. The total weight of the pack-mounted receiver, including generator and insulated container, is $22 \mathrm{~kg}$.

Our system is less complicated to assemble than other portable digitally recording ice-radar receivers (Jacobel and others, 1988; Jones and others, 1989), because commercial components are used and no custom engineering effort is required. Our system is inexpensive: the total cost, including the lap-top PC, is less than \$2000 U.S. Our system is versatile, because the presence of an IBM-compatible personal computer (PC) in the field allows many software options for data acquisition, display, and processing.

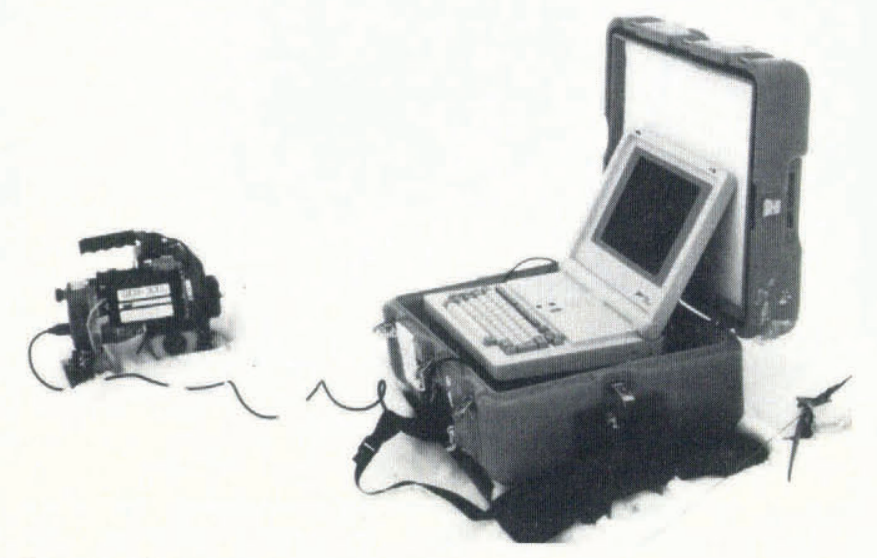

Fig. 1. The PC-based ice-radar receiver in operation on Mount Estelle glacier, Alaska, U.S.A.

\section{SYSTEM COMPONENTS}

The radar pulse is generated by a resistively loaded dipole antenna excited by a high-voltage pulse generator. The direct and reflected radar wave forms are digitized and stored by the oscilloscope and lap-top PC. A block diagram of an ice-radar system using the PC-based receiver is shown in Figure 2. Specifications for the receiver are given in Table I.

\section{Antennas}

We use resistively loaded center-fed dipole antennas following the U.S. Geological Survey design (Watts and England, 1976; Watts and Wright, 1981). We depart from the original design only by incorporating a small nylon cord into each antenna arm and binding the cord and the antenna together with clear polyolefin shrink tubing. The antenna arms are thus very strong and durable, quickly repaired if broken (rarely), and easily coiled into a compact form.

\section{Digital storage oscilloscope}

Recent developments in wave-form digitization technology have led to inexpensive computer-controlled oscilloscopes. These devices interface with a PC through a serial port or logic bus and use computer software to display, store, and process the signal. For repetitive signals, such as radar echoes, digital oscilloscopes can achieve very short sampling intervals by using equivalent time sampling. This means that only one sample is taken each time the oscilloscope is triggered. This is not a serious limitation for our system because our transmitter produces 10000 pulses/s. An entire 512 point wave form can be acquired in $52 \mathrm{~ms}$.

We chose to use a Heath SC-4802 Computer Oscilloscope as the wave-form digitizer in our ice-radar receiver mainly because it can be used with any lap-top

DIGITAL RADAR SYSTEM

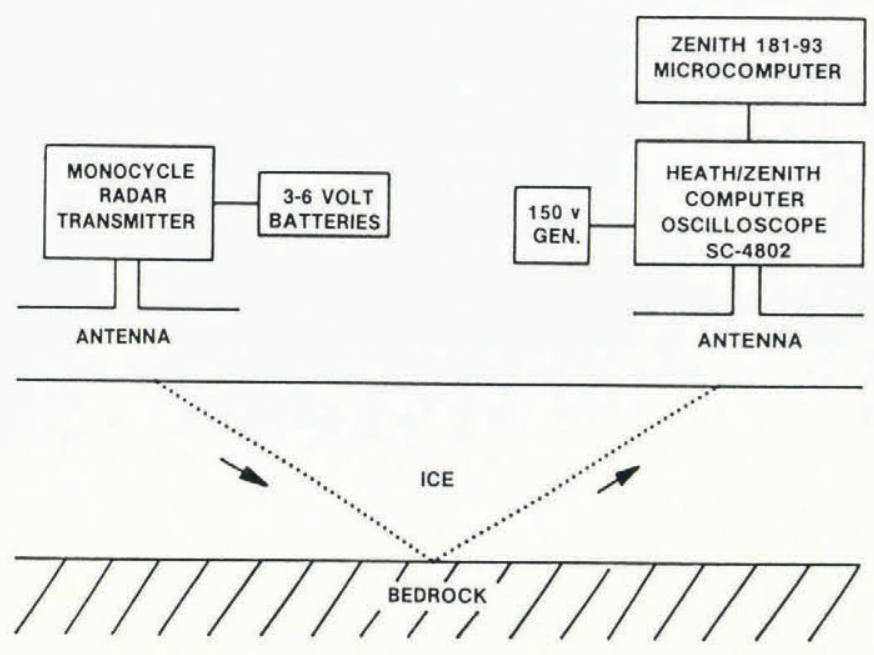

Fig. 2. Block diagram of an ice-radar system including the $P C$-based receiver. 
TABLE I. RECEIVER SPECIFICATIONS

\section{Receiver}

\begin{tabular}{|c|c|}
\hline Model number & Heath SC4802/4850 \\
\hline Input impedance & $1 \mathrm{~m} \Omega$ \\
\hline Total voltage gain & 125 \\
\hline Attenuator & 29 steps in a $1-2-5$ sequence \\
\hline Vertical sensitivity & $5 \mathrm{mV} /$ division \\
\hline Vertical accuracy & $5 \% \pm 2$ bits \\
\hline Amplitude resolution & 8 bits \\
\hline Band width & $2 \mathrm{~Hz}$ to greater than $90 \mathrm{MHz}$ \\
\hline $\begin{array}{l}\text { Time to gather one } \\
\text { record }\end{array}$ & $52 \mathrm{~ms}$ \\
\hline $\begin{array}{l}\text { Time to store one } \\
\text { record }\end{array}$ & ( \\
\hline $\begin{array}{l}\text { Number of samples } \\
\text { per record }\end{array}$ & 512 \\
\hline Time-base accuracy & $5 \% \pm 2$ bits \\
\hline Sampling interval & $200 \mathrm{ps}$ minimum \\
\hline CPU & 80 C88 (computer), Z80 (scope) \\
\hline Memory & 640 kbytes of RAM \\
\hline Clock speed & $8 \mathrm{MHz}$ (computer), $4 \mathrm{MHz}$ (scope) \\
\hline Inputs/outputs & $\begin{array}{l}\text { Computer keyboard } \\
640 \times 200 \text { pixel backlit LCD screen } \\
2 \text {-channel oscilloscope inputs } \\
9600 \text { baud RS-232C serial interface } \\
\text { Two } 3.5 \text { in }(9 \mathrm{~cm}) \text { DS-DD micro- } \\
\text { diskettes }\end{array}$ \\
\hline Attributes & $\begin{array}{l}\text { Wave-form stacking ( } 1-250 \text { stacks) } \\
\text { cursor measurement of wave form } \\
\text { wave-form comparison (memory) } \\
\text { software written in BASIC }\end{array}$ \\
\hline Power requirements & $\begin{array}{l}48 \mathrm{~W} \text { at } 120 \mathrm{~V} \text { a.c. (oscilloscope) } \\
12.6 \mathrm{~W} \text { at } 18 \mathrm{~V} \text { d.c. (computer) }\end{array}$ \\
\hline Power supply & $\begin{array}{l}\text { Tanaka QEG }-300 \text { generator } \\
300 \mathrm{~W} \text { at } 120 \mathrm{~V} \text { a.c. } \\
120 \mathrm{~W} \text { at } 12 \mathrm{~V} \text { d.c. }\end{array}$ \\
\hline Weight & $22 \mathrm{~kg}$ \\
\hline
\end{tabular}

IBM-compatible PC with a standard RS-232C serial interface. All other computer oscilloscopes that we know of require internal expansion cards in the PC and thus would not work with most lap-tops.

The Heath unit has several additional characteristics that make it suitable for use in an ice-radar receiver:

1. The oscilloscope accurately samples radar wave forms in the frequency range appropriate for ice radar $(1-20 \mathrm{MHz})$ at a sampling interval as short as $0.2 \mathrm{~ns}$.

2. The unit has a vertical resolution of 8 bits ( 1 part in 256 ), a value comparable to the best analog oscilloscope screens.

3. The sampling circuits can be reached only by signals below $100 \mathrm{MHz}$. Thus, alias-free measurements can be assured simply by using a sampling interval less than $5 \mathrm{~ns}$.

4. The record length is 512 digital samples, sufficient for many ice-radar applications.

5. The unit allows interactive cursor measurements of time and voltage, thus allowing accurate determinations of reflection times and amplitudes in the field.

6. The instrument, which draws $48 \mathrm{~W}$, can be powered by a very light-weight a.c./d.c. generator or can be modified for use with batteries.

7. The oscilloscope costs less than $\$ 300$ U.S.

A limitation of the Heath computer oscilloscope is that it does not contain a delay line. This means that some data immediately after the trigger point will be lost. According to the manufacturer, the amount of lost data depends on the sampling interval: at a $4 \mathrm{~ns}$ sampling interval, $345 \mathrm{~ns}$ of data are lost; at a $0.2 \mathrm{~ns}$ sampling interval, $80 \mathrm{~ns}$ of data are lost. We verified these delay times by laboratory tests.

\section{Lap-top PC}

The computer oscilloscope interfaces directly with a lap-top PC through a RS-232C serial interface. We use a Zenith 181-93 lap-top computer. However, any batterypowered IBM-compatible lap-top computer with a RS-232C serial interface, Color Graphics Adapter (CGA) screen, and floppy drive could be used. The computer screen functions as a display monitor in the field and signals can be viewed in near-real time as they are collected.

The digitized wave forms, along with oscilloscope parameters, are stored as files on floppy disks. Although other researchers have reported problems with floppy disks in the field, we had no problems with $3 \frac{1}{2}$ in $(9 \mathrm{~cm})$ diskettes at temperatures of $2-3^{\circ} \mathrm{C}$. Using the software supplied with the oscilloscope, approximately 270 radar wave forms can be sorted on a 720 kbyte diskette. However, because each record consists of exactly 512 data bytes plus 5 parameter bytes, data compression could increase the number of records per diskette to over 1400 .

The presence of a PC in the field provides considerable versatility:

1. Signals can be stacked to any desired degree before storage.

2. Signal processing can be accomplished in the field using a wide variety of existing software for IBM-compatible computers.

3. Previously collected wave forms and cross-sections can be displayed at any time.

4. The operator can use the computer to record field observations and survey information.

\section{FIELD TEST}

The receiver was successfully field tested on Mount Estelle glacier in Alaska in 1988. Approximately 150 soundings were made to determine the ice thickness of the glacier and to map power-reflection coefficients of the icebedrock interface (Hammond, unpublished). A pulse generator, based on the U.S. Geological Survey design, was used (Watts and England, 1976; Watts and Wright, 1981). Resistively loaded dipole antennas, separated by $30 \mathrm{~m}$, were deployed in the broadside parallel mode. Spectral analysis of a typical bedrock reflection indicated reflection peak power at $2.86 \mathrm{MHz}$ (Fig. 3). We found the wave-form stacking feature useful for eliminating radio-frequency interference caused by the generator, other geophysical equipment in operation, and FM radio transmissions. Air temperatures of $2-3^{\circ} \mathrm{C}$ did not adversely affect operation of either the computer or the oscilloscope. Light precipitation fell during one period but was dealt with by covering the operator and radar receiver with a clear plastic sheet.

The records along a bottom-echo profile at the test site were $2 \mu \mathrm{s}$ in length and were digitally sampled at a $4 \mathrm{~ns}$ interval (Fig. 4). Although the oscilloscope triggered on the onset of the air wave at the receiving antenna, zero time on the traces was set at the impulse time in the transmitter.

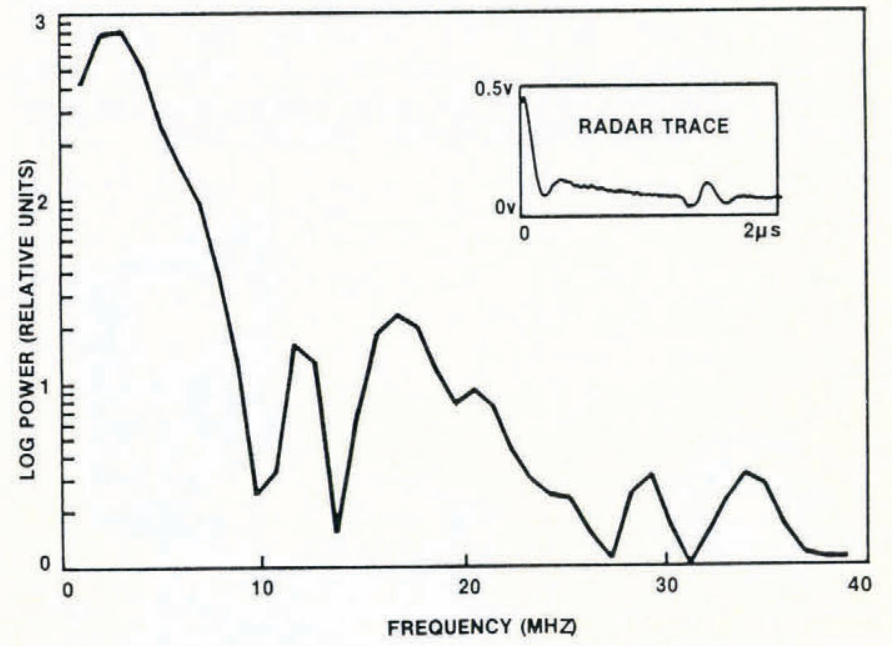

Fig. 3. A typical digital wave form recorded on Mount Estelle glacier, Alaska, and its power spectrum. The $P C$-based receiver allows the use of $a$ wide variety of standard signal-analysis software in the field. 
